\title{
New Catalytic Activity of Insoluble Polymer-Supported Crown Ethers for Addition Reaction of Oxirane with Active Ester
}

\author{
Tadatomi Nishikubo, ${ }^{\dagger}$ Yoriatsu Sugimoto, and Masao TomoI* \\ Department of Applied Chemistry, Faculty of Engineering, \\ Kanagawa University, Kanagawa-ku, Yokohama 221, Japan \\ *Department of Applied Chemistry, Faculty of Engineering, \\ Yokohama National University, Hodogaya-ku, Yokohama 240, Japan
}

(Received June 11, 1991)

\begin{abstract}
Regioselective addition reaction of phenyl glycidyl ether with S-phenyl thioacetate was carried out using the complex catalyst of the polymer-supported crown ether with potassium phenoxide in aprotic polar solvents, and the corresponding adduct 2-acetoxy-3-(phenylthio)-propyl phenyl ether was obtained in high yield with small amounts of by-product 2-hydroxy-3-(phenylthio)propyl phenyl ether. Furthermore, it was found that the rate of the reaction and yield of the adduct were affected by the degree of introduction of the crown ether residue, the degree of crosslinking of the polystyrene bead, the reaction solvent, and the kind of potassium salt.
\end{abstract}

KEY WORDS Polymer-Supported Crown Ether / New Catalytic Activity /

Regioselective Addition Reaction / Phenyl Glycidyl Ether / S-Phenyl

Thioacetate /

Polymer-supported crown ethers have been used for separations ${ }^{1-4}$ of some metal cations, anions, and organic compounds in analytical chemistry. It is also well-known ${ }^{5-8}$ that insoluble polystryrene beads carrying pendant crown ether groups as well as pendant quaternary ammonium or phosphonium salts can be used as phase transfer catalysts in liquid-solidliquid or solid-liquid-solid heterogeneous organic synthesis. The complex of polymer-supported crown ether with cobalt has also been used as a catalyst ${ }^{9}$ for aldol condensation reactions.

Recently, we found ${ }^{10-12}$ a new kind of

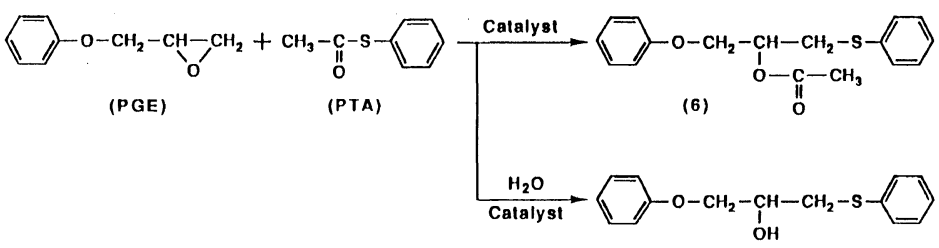

(7)

Catalyst 1, 2 and 3 :

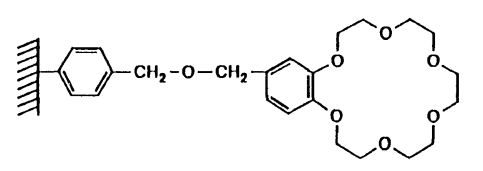

Catalyst 4 and 5 :

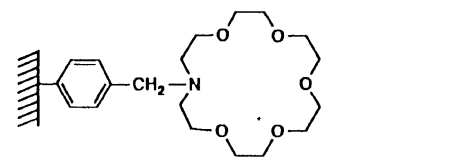

Scheme 1. 
catalytic behavior of quaternary ammonium salts, quaternary phosphonium salts, and complexes of crown ethers with alkali metal salts for regioselective addition reaction of epoxy compounds with certain esters and thioesters. In previous papers, we reported that insoluble polymer-supported catalysts containing pendant quaternary ammonium or phosphonium salts, ${ }^{13,14}$ and ( $N, N$-dimethylamino)pyridine moiety, ${ }^{15}$ have high catalytic activity for the above addition reaction. These polymer-supported catalysts can be seperated easily from the reaction mixtures and can be reused.

In this paper, we report new catalytic activity of complexes of insoluble polystyrene-supported crown ethers with certain potassium salts for the addition reaction of phenyl glycidyl ether (PGE) with $S$-phenyl thioacetate (PTA).

\section{EXPERIMENTAL}

\section{Materials}

Characteristics of the crosslinked polystyrene beads containing crown ether moieties, which were prepared previously ${ }^{16}$ as polymersupported phase-transfer catalysts, are summarized in Table I. PGE and reaction solvents were used after distillation on $\mathrm{CaH}_{2}$. PTA was synthesized by the reaction of thiophenol with acetyl chloride and then purified as reported. ${ }^{17}$ Commercial 18-crown-6 (18-C-6) was used

Table I. Characterization of polystyrene beads containing pendant crown ether

\begin{tabular}{|c|c|c|c|}
\hline Catalyst & $\begin{array}{c}\mathrm{DC}^{\mathrm{a}} \\
\text { of bead }\end{array}$ & $\begin{array}{c}\text { Halogen } \\
\text { in bead }\end{array}$ & $\begin{array}{l}\text { DRS }^{\mathbf{b}} \\
\text { of bead }\end{array}$ \\
\hline & $\%$ & mequiv $\mathrm{g}^{-1}$ & $\%$ \\
\hline 1 & 2 & 0.65 & 9 \\
\hline 2 & 2 & 1.05 & 16 \\
\hline 3 & 2 & 1.47 & 34 \\
\hline 4 & 2 & 1.10 & 17 \\
\hline 5 & 4 & 1.13 & 18 \\
\hline
\end{tabular}

${ }^{a}$ Degree of crosslinking.

${ }^{b}$ Degree of ring substitution. without further purification. Potassium phenoxide $(\mathrm{PhOK})$ was prepared by the reaction of potassium hydroxide with phenol in methanol, and then recrystallized twice from ethyl methyl ketone.

\section{Measurement of the Rate of Regioselective} Addition Reaction of PGE with PTA

Appropriate amounts of polymer-supported crown ether with a particle size of $100-200$ mesh, PhOK, PTA, a solvent, and $p$-dichlorobenzene (internal standard for GLC analysis) were charged into reaction flasks kept at a temperature with stirring under dry argon for $1 \mathrm{~h}$. To the mixture was added a certain amount of oxirane PGE to start the reaction. The reaction mixtures were periodically analyzed by the GLC method.

\section{Equipment}

GLC analysis was carried out on a Shimadzu Model GC-9AM gas chromatograph with a $3 \mathrm{~mm} \times 2.6 \mathrm{~m}$ column packed with $3 \%$ Silicon OV-101 on Shimalite W (AW-MDCS).

\section{RESULTS AND DISCUSSION}

The addition reaction of PGE with PTA proceeded regioselectively to give the corresponding adduct 2-acetoxy-3-(phenylthio)propyl phenyl ether (6) with small amounts of by-product, 2-hydroxy-3-(phenylthio)propyl phenyl ether (7), by complex $(1 \mathrm{~mol} \%)$ of polymer-supported crown ether $\mathbf{2}$ with a particle size of $100-200$ mesh and $\mathrm{PhOK}$ in DMF, and the yield of product 6 increased with reaction temperature (Figure 1).

Figure 1 also suggests that the observed rate of the reaction obeyed first-order kinetics to the PTA concentration (and to the PGE concentration) and various temperatures as does the reaction ${ }^{13,14}$ of PGE with PTA in the presence of insoluble polymer-supported quaternary onium salts as catalysts. However, it seems that there is such indistinct factor as induction period in the reaction, especially, at 


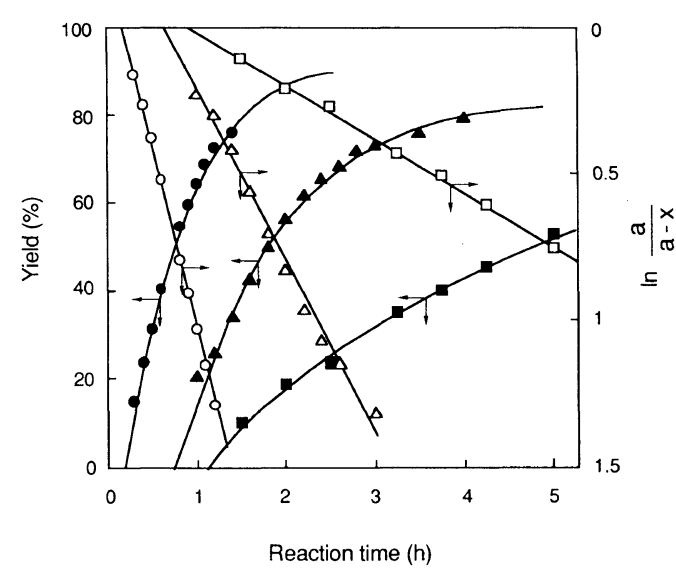

Figure 1. Rate of the reaction of PGE ( $4 \mathrm{mmol}$ ) with PTA $(4 \mathrm{mmol})$ in the presence of polymer-supported crown ether $2(1 \mathrm{~mol} \%)$ and PhOK $(1 \mathrm{~mol} \%)$ in DMF $(2 \mathrm{ml})$ at various temperatures: $(\square, \boldsymbol{\square})$ at $80^{\circ} \mathrm{C} ;(\triangle, \boldsymbol{\Delta})$ at $90^{\circ} \mathrm{C}$; $(\mathrm{O}, \mathbf{O})$ at $100^{\circ} \mathrm{C} . a=[\mathrm{PTA}]_{\text {initial }} ; x=[\mathrm{PTA}]_{\text {decreased }}$.

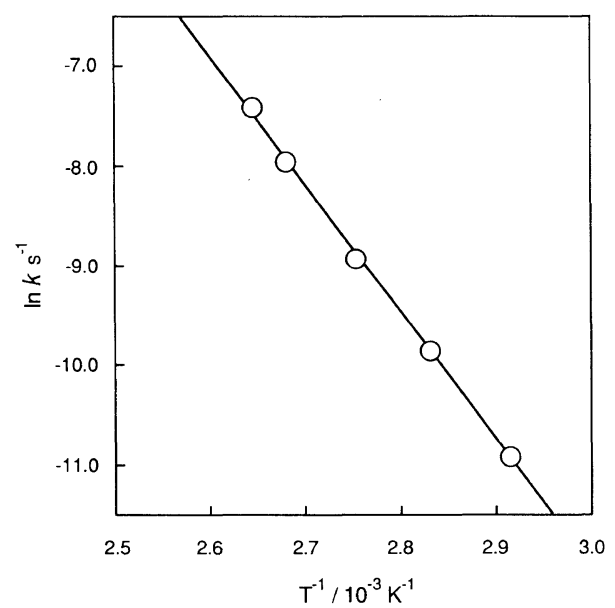

Figure 2. Arrhenius plots of the observed pseudo-firstorder rate constant on the reaction of PGE with PTA using complex catalyst of polymer-supported crown ether $\mathbf{2}$ with $\mathrm{PhOK}$.

low reaction temperature.

Arrhenus plots based on the above-observed pseudo-first-order rate constant $k_{1}$ of the reaction are shown in Figure 2, and the apparent activation energy of the reaction of PGE with PTA catalyzed by the complex of the polymer-supported crown ether with $\mathrm{PhOK}$ was estimated as $98.07 \mathrm{kJmol}^{-1}$, which is

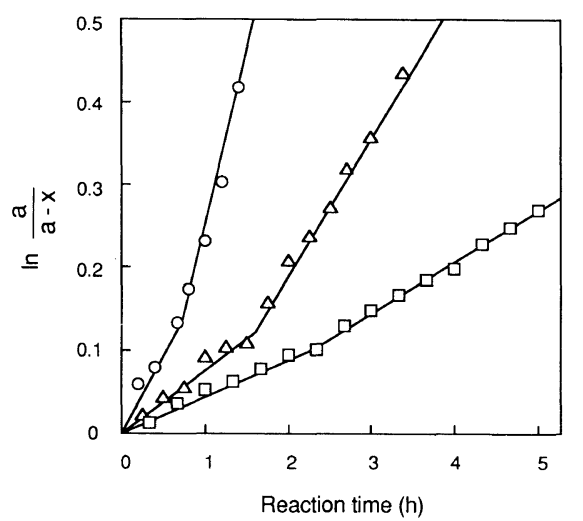

Figure 3. First-order plots of the reaction of PGE ( $4 \mathrm{mmol}$ ) with PTA ( $4 \mathrm{mmol}$ ) by using the complex catalyst of polymer-supported crown ether $2(1 \mathrm{~mol} \%)$ with PhOK $(1 \mathrm{~mol} \%)$ in DMF $(2 \mathrm{~mL})$ at various temperatures: $(\square)$ at $70^{\circ} \mathrm{C} ;(\triangle)$ at $80^{\circ} \mathrm{C} ;(\bigcirc)$ at $90^{\circ} \mathrm{C}$.

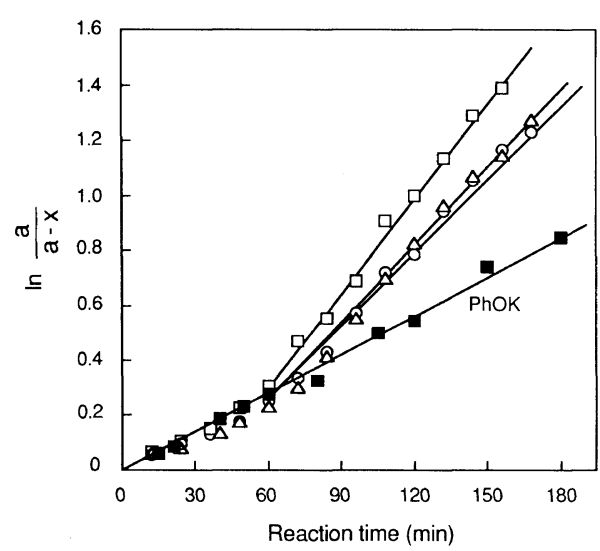

Figure 4. First-order plots of the reaction of PGE $(4 \mathrm{mmol})$ with PTA $(4 \mathrm{mmol})$ by using various catalysts $(1 \mathrm{~mol} \%)$ in DMF $(2 \mathrm{ml})$ at $90^{\circ} \mathrm{C}$ : $(\square)$ with $\mathrm{PhOK}$; $(\mathrm{O})$ with polymer-supported crown ether 1 and $\mathrm{PhOK} ;(\triangle)$ with polymer-supported crown ether 2 and PhOK; ( $\square$ ) with polymer-supported crown ether $\mathbf{3}$ and PhOK.

mostly the same as the activation energy $\left(101.7 \mathrm{kJmol}^{-1}\right)$ in the reaction using the complex of low molecular weight $18-\mathrm{C}-6$ with $\mathrm{PhOK}$ as a catalyst.

To clarify the catalytic activity of the complex of the polymer-supported crown ether with $\mathrm{PhOK}$, detailed correlations between the reaction times and reaction rates are summarized in Figure 3. The rates of reaction obey- 
ed first order kinetics at 70,80 , and $90^{\circ} \mathrm{C}$, respectively. Furthermore, break points were found in each plot, although remarkable break points were not found ${ }^{18}$ in the reaction of PGE and PTA using complex catalysts of low molecular weight crown ethers with PhOK. Therefore, further reactions of PGE with PTA were carried out in DMF at $90^{\circ} \mathrm{C}$ using polymer-supported crown ethers 1, 2, and 3 with $\mathrm{PhOK}$, and only $\mathrm{PhOK}$ as catalyst systems (Figure 4). When the reaction was performed in DMF with $1 \mathrm{~mol} \%$ of PhOK as the catalyst, the reaction rate of $\mathrm{PGE}$ with $\mathrm{PTA}$ was relatively slow, and the brake point on the reaction was not found. However, break points appeared about $60 \mathrm{~min}$ after the start of each reaction using polymer-supported crown ethers 1, 2, and 3 with PhOK. Each rate of the reaction with complex catalysts of the polymersupported crown ethers with PhOK obeyed exactly first order kinetics.

This means that the break points in Figure 4 were induction periods to form new catalytic species from the polymer-supported crown ethers with $\mathrm{PhOK}$ at $90^{\circ} \mathrm{C}$ in $\mathrm{DMF}$. This also indicates that the first slopes of the reactions at 70,80 , and $90^{\circ} \mathrm{C}$ suggested in Figure 3 were the rates of PGE with PTA catalyzed by only $\mathrm{PhOK}$, and the second slopes after the brake points were the rates of PGE with PTA catalyzed by the complex of the polymer-supported crown ether with PhOK. Therefore, an indistinct phenomenon as an induction period indicated in Figure 1 could be also explained from the above results.

Hence, the catalytic activity of the polymersupported crown ether complexes can be evaluated from the observed pseudo-first-order rate constant in the reaction, although yields of main product 6 and by-product 7 on the reaction are also very important to evaluate catalytic activity.

As summarized in Table II, although the catalytic activities of the complexes of the polymer-supported crown ethers with $\mathrm{PhOK}$ were higher than that of $\mathrm{PhOK}$ in $\mathrm{DMF}$, the
Table II. Catalytic activity of the polymer-supported crown ethers for the addition reaction of PGE with PTA ${ }^{a}$

\begin{tabular}{|c|c|c|c|c|}
\hline \multirow{2}{*}{$\begin{array}{c}\text { Run } \\
\text { no. }\end{array}$} & \multirow{2}{*}{$\begin{array}{c}\text { Crown } \\
\text { ether }\end{array}$} & Yield of 6 & Yield of 7 & $k_{\text {obsd }}$ \\
\hline & & $\%$ & $\%$ & $\times 10^{-4} \mathrm{~s}^{-1}$ \\
\hline 1 & None & 75.8 & 12.4 & 0.78 \\
\hline 2 & $18-C-6$ & 87.6 & 12.3 & 6.16 \\
\hline 3 & 1 & 84.4 & 11.5 & $1.62(3.52)^{b}$ \\
\hline 4 & 2 & 82.2 & 11.9 & $1.81(3.17)^{b}$ \\
\hline 5 & 3 & 86.5 & 10.5 & $1.96(2.73)^{b}$ \\
\hline 6 & 4 & 83.5 & 10.0 & $1.59(2.24)^{b}$ \\
\hline 7 & 5 & 87.4 & 8.6 & $0.98(1.44)^{\mathrm{b}}$ \\
\hline
\end{tabular}

a The reaction was carried out with $4 \mathrm{mmol}$ of PGE and $4 \mathrm{mmol}$ of PTA in $2 \mathrm{ml}$ of DMF using $0.04 \mathrm{mmol}$ of crown ether and $0.04 \mathrm{mmol}$ of $\mathrm{PhOK}$ at $90^{\circ} \mathrm{C}$ for $5 \mathrm{~h}$.

b The reaction was carried out using $0.2 \mathrm{mmol}$ of the polymer-supported crown ether and $0.04 \mathrm{mmol}$ of PhOK.

activities of the former catalysts were lower than that of the catalyst complex of low molecular weight crown ether 18-C-6 with PhOK under the same condition.

When the reaction was carried out using the complex catalyst with $1 \mathrm{~mol} \%$ of the polymersupported crown ethers and $1 \mathrm{~mol} \%$ of PhOK, the catalytic activity of the polymer-supported crown ether complexes (see Run no. 3-5) was affected slightly by the degree of ring substitution. That is, the activity increased gradually with increasing degree of the ring substitution.

The catalytic activity decreased with increase in the ring substitution, when the reaction was performed using the complex catalyst with 5 mol $\%$ of the polymer-supported crown ethers and $1 \mathrm{~mol} \%$ of PhOK. This means that the hydrophobicity of the polystyrene-beads always decreases with increase in the number of the pendant complex. Similar results were obtained $^{14}$ in the reaction using polymersupported quaternary onium salts as the catalysts.

The catalytic activity of the polymersupported crown ethers was also affected by the degree of crosslinking of the polymer, and the crown ether carried on the polymer of low 


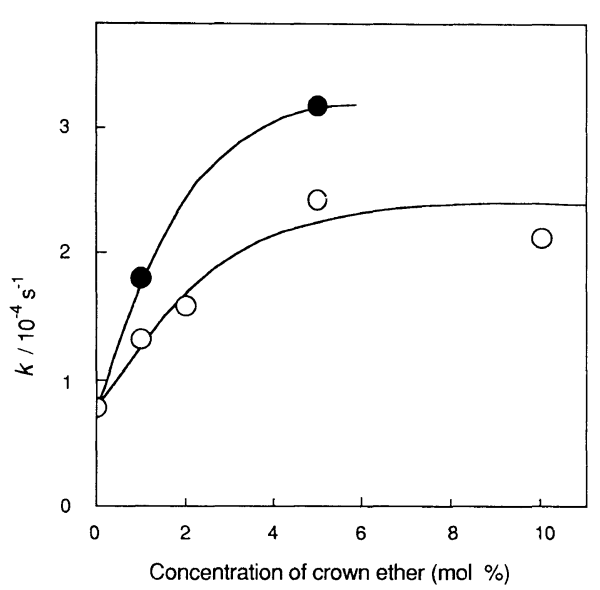

Figure 5. Correlation between crown ether concentration and observed pseudo-first-order rate constant: The reaction was carried out with $4 \mathrm{mmol}$ of PGE and $4 \mathrm{mmol}$ of PTA in the presence of $1 \mathrm{~mol} \%$ of $\mathrm{PhOK}$ and various amounts of polymer-supported crown ether 2 in DMF $(2 \mathrm{ml})$ at $90^{\circ} \mathrm{C}$ : (O) with size-controlied particle $(100$ 200 mesh); $(\bigcirc)$ with non-size-controlled particles.

degree of crosslinking had higher catalytic activity than that on the polymer of high degree of crosslinking (see Run no. 6 and 7).

As shown in Figure 5, the observed rate of the reaction of PGE with PTA increased with increasing concentration of the polymersupported catalyst $\mathbf{2}$, and then leveled off above $5 \mathrm{~mol} \%$. This indicates that the complex was formed sufficiently by mixing of 5 parts of the polymer-supported crown ether and one part of $\mathrm{PhOK}$ in DMF, whereas the equimolar mixture did not supply an effective amount of the complex. Therefore, the observed rates of the reaction were relatively enhanced when $5 \mathrm{~mol} \%$ of the polymer-supported crown ether and $1 \mathrm{~mol} \%$ of PhOK were used as the catalyst systems.

Figure 5 also suggests that the polymersupported crown ether $\mathbf{2}$ with size-controlled particles (100-200 mesh) had higher catalytic activity than the polymer composed from non-size-controlled particles. However, detailed correlation between the catalytic activity of the polymer-supported crown ether and the particle size of the polystyrene bead could not
Table III. Solvent effects for the addition reaction of PGE with PTA using polymer-supported catalyst $2^{\mathrm{a}}$

\begin{tabular}{|c|c|c|c|c|}
\hline \multirow{2}{*}{$\begin{array}{l}\text { Run } \\
\text { no. }\end{array}$} & \multirow{2}{*}{$\begin{array}{l}\text { Reac- } \\
\text { tion } \\
\text { solvent }\end{array}$} & $\begin{array}{c}\text { Dipolar moment } \\
\text { of solvent }\end{array}$ & \multirow{2}{*}{$\frac{\text { Yield of } 6}{\%}$} & \multirow{2}{*}{$\frac{\text { Yield of } 7}{\%}$} \\
\hline & & D & & \\
\hline 8 & DMSO & 4.3 & 85.6 & 14.3 \\
\hline 9 & NMP & 4.09 & 67.5 & 19.4 \\
\hline 10 & DMF & 3.86 & 82.2 & 11.9 \\
\hline 11 & Diglyme & 1.97 & $7.2(57.1)^{\mathrm{b}}$ & $2.9(8.2)^{\mathrm{b}}$ \\
\hline 12 & $\begin{array}{l}\text { Chloro- } \\
\text { benzene }\end{array}$ & 1.54 & $3.5(55.0)^{\mathrm{b}}$ & $2.3(3.9)^{\mathrm{b}}$ \\
\hline 13 & Anisole & 1.20 & $2.7(19.7)^{b}$ & $2.1(3.2)^{\mathbf{b}}$ \\
\hline 14 & Toluene & 0.37 & $0.3(78.9)^{b}$ & $0.2(4.1)^{b}$ \\
\hline
\end{tabular}

a $4 \mathrm{mmol}$ of crown ether and $4 \mathrm{mmol}$ of potassium salt was stirred in $1 \mathrm{ml}$ of solvent for $1 \mathrm{~h}$ at room temperature, and the the reaction was carried out with $4 \mathrm{mmol}$ of PGE and $4 \mathrm{mmol}$ of PTA in $2 \mathrm{ml}$ of solvent at $90^{\circ} \mathrm{C}$ for $5 \mathrm{~h}$.

b The reaction was carried out for $24 \mathrm{~h}$.

be determined from this data.

As summarized in Table III, the addition reaction of PGE with PTA proceeded to give adduct 6 in high yields in aprotic polar solvents such as DMSO, NMP, and DMF containing polymer-supported crown ether 2 with PhOK. The catalyst was less effective in diglyme, chlorobenzene, anisole, and toluene. The reaction, however, produced adduct 6 in high yields in $24 \mathrm{~h}$ using the complex catalyst of polymer-supported crown ether 2 with $\mathrm{PhOK}$ in toluene. This indicates that the addition reaction of PGE with PTA using the complex catalyst of the polymer-supported crown ether with $\mathrm{PhOK}$ was strongly affected by the rate of formation of the complex in the solvent, and that the aprotic polar solvents such as DMF and DMSO have relatively high effect as to make the complex. Therefore, the reaction proceeded with high reaction rate during the initial $5 \mathrm{~h}$ in the aprotic polar solvents. Although the initial reaction rate of $\mathrm{PGE}$ with PTA is very small in toluene, the reaction rate increases gradually because of the increase of the new catalytic species formed by the complexation of the polymer-supported crown 
Table IV. Effects of counter anion on the complex catalyst of the polymer-supported crown ether with salts ${ }^{\mathrm{a}}$

\begin{tabular}{|c|c|c|c|c|}
\hline \multirow{2}{*}{$\begin{array}{c}\text { Run } \\
\text { no. }\end{array}$} & \multirow{2}{*}{ Salt } & Yield of 6 & Yield of 7 & $k_{\text {obsd }}$ \\
\hline & & $\%$ & $\%$ & $\times 10^{-4} \mathrm{~s}^{-1}$ \\
\hline 15 & PhOK & $82.2(75.8)^{b}$ & $11.9(12.4)^{\mathbf{b}}$ & $1.81(0.78)^{b}$ \\
\hline 16 & $\mathrm{KF}$ & $71.4(24.2)^{\mathrm{b}}$ & $6.3(9.6)^{b}$ & 0.78 (very slow) \\
\hline 17 & $\mathrm{KSCN}$ & $42.8(66.1)^{b}$ & $24.8(25.9)^{\mathrm{b}}$ & $0.42(1.23)^{\mathrm{b}}$ \\
\hline
\end{tabular}

a $4 \mathrm{mmol}$ of polymer-supported crown ether 2 and $4 \mathrm{mmol}$ of potassium salt was stirred in $1 \mathrm{ml}$ of DMF for $1 \mathrm{~h}$ at room temperature, and the reaction was carried out with $4 \mathrm{mmol}$ of PGE and $4 \mathrm{mmol}$ of PTA in $2 \mathrm{ml}$ of DMF at $90^{\circ} \mathrm{C}$ for $5 \mathrm{~h}$.

b The reaction was carried out without a crown ether.

\section{ether with $\mathrm{PhOK}$.}

The catalytic activity of the complexes of the polymer-supported crown ether with certain potassium salts such as $\mathrm{PhOK}, \mathrm{KF}$, and $\mathrm{KSCN}$ was evaluated in the reaction of PGE with PTA in DMF. As summarized in Table IV, although the catalytic activity of $\mathrm{KF}$ as well as $\mathrm{PhOK}$ increased by the addition of the polymersupported crown ether in this condition, the activity of KSCN decreased strongly by the addition of the polymer-supported crown ether. That is, a suitable combination between the polymer-supported crown ethers and alkali metal salts may also be important to form a complex catalyst with high activity for the regioselective addition reaction of epoxy compounds with active esters.

From the above results, it was concluded that the regioselective addition reaction of epoxy compound PGE with active ester PTA proceeded successfully using the complex catalysts of polymer-supported crown ethers with certain organic or inorganic salts such as $\mathrm{PhOK}$ and $\mathrm{KF}$ as catalysts in aprotic polar solvents.

\section{REFERENCES}

1. E. Blasius, K. P. Janzen, M. Keller, H. Lander, T. Nguyen-Tien, and G. Scholten, Talanta, 27, 107 (1980).

2. E. Blasius, K. P. Janzen, W. Adrian, W. Klein, H. Klotz, H. Luxemburger, E. Mernke, V. B. Nguyen, T. Nguyen-Tien, R. Rausch, J. Stockemer, and A. Toussaint, Talanta, 27, 127 (1980).

3. M. Igawa, K. Saito, J. Tsukamoto, and M. Tanaka, Anal. Chem., 53, 1942 (1981).

4. M. Nakajima, K. Kimura, and T. Shono, Anal. Chem., 55, 463 (1983).

5. F. Montanari and P. Tundo, J. Org. Chem., 46, 2125 (1981).

6. P. Tundo and P. Venturello, J. Am. Chem. Soc., 103, 856 (1981).

7. K. Fukunishi, B. Czech, and S. L. Regen, J. Org. Chem., 46, 1218 (1981).

8. M. Tomoi, N. Yanai, S. Shiiki, and H. Kakiuchi, $J$. Polym. Sci., Polym. Chem. Ed., 22, 911 (1984).

9. K. Zhang, G. S. Kumar, and D. C. Neckers, J. Polym. Sci., Polym. Chem. Ed., 23, 1293 (1985).

10. T. Nishikubo, T. Iizawa, and S. Saita, E. Takahashi, and F. Nono, Macromolecules, 18, 2131 (1985).

11. T. Iizawa, A. Goto, and T. Nishikubo, Bull. Chem. Soc. Jpn., 62, 597 (1989).

12. T. Nishikubo and K. Sato, Chem. Lett., 697 (1991).

13. T. Nishikubo, T. Iizawa, M. Shimojyo, T. Kato, and A. Shiina, J. Org. Chem., 55, 2536 (1990).

14. T. Nishikubo, T. Kato, Y. Sugimoto, M. Tomoi and S. Ishigaki, Macromolecules, 23, 3406 (1990).

15. T. Nishikubo, T. Kato, M. Tomoi, and S. Ishigaki, Polym. J., 21, 669 (1989).

16. M. Tomoi, N. Yamai, S. Shiiki, and H. Kakiuchi, $J$. Polym. Sci., Polym. Chem. Ed., 22, 911 (1984).

17. K. Miyaki and S. Yamagishi, J. Pharam. Soc. Jpn., 76, 436 (1956).

18. T. Nishikubo, Y. Sugimoto, and K. Sato, Nippon Kagaku Kaishi, in press. 